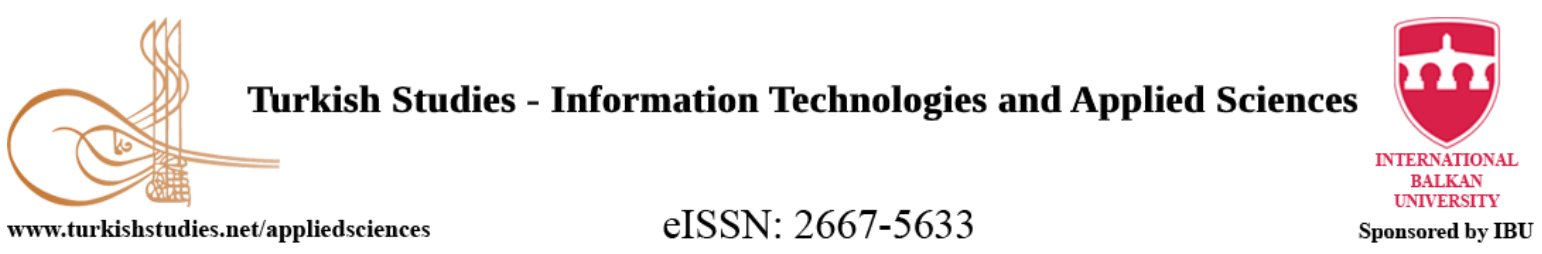

Research Article / Araştırma Makalesi

\title{
Türkiye ve Güney Afrika Eğitim Sistemlerinin: Okullarda Bilgi ve İletişim Teknolojisi Uygulamalarına Göre Karşılaştırılması
}

\author{
The Comparison of Turkish and South African Education Systems in Schools According to \\ Information and Communication Technology Implementations
}

\author{
Mehmet Ülker*
}

\begin{abstract}
The purpose of this study is to compare the similarities and differences between the information and communication technology implementations of Turkish and South African education systems. This study was conducted according to the qualitative research method. It is a descriptive study and the case study pattern of qualitative research method was used in the study. The data was obtained through document analysis and was analyzed by the method of interpretation. The findings of the study are gathered under two main titles. The first of these is the findings around Turkey and South Africa's demographic and social development indicators and the limited numerical data of these two countries' around education. The second is the findings regarding the availability of the information and communication technologies in the education system. This second process also includes the aim, the philosophical background of the curriculum as well as the availability of the information and communication technologies as compulsory and elective courses and their weekly hours in it. According to the results of this study, quantitatively Turkey has better indicators in comparison to South Africa. Both countries have done similar implementations, however Turkey's efforts regarding utilization of the information and communication technologies in the education system are pioneering and more. Besides, while in South Africa the names of the courses, their status of being compulsory or elective was almost always constant, in Turkey these changes were experienced continuously. At the end of this study, since the scope and limitations of it did not provide the opportunity to subject the study to in-depth and detailed analysis it was suggested that it would be appropriate to carry out new and more detailed analysis studies by employing it's different elements.
\end{abstract}

Structured Abstract: Introduction: This study has gravitated towards the comparison between the Turkish and South African education system based on Information and Communication Technology (ICT). In this context, through document analysis findings were obtained around Turkey's and South Africa's demographic and social development indicators. Similarly, the compilation of the education-related numerical data of these two countries and the data of ICT-based education programs is planned. The data includes the philosophical background, the purpose of the ICT curriculum in both countries, it also includes the compulsory and elective status, weekly course hours (loads) of the ICT courses. In this context, as Erdogan (2003) stated, this study was considered "important for the discovery of other or counter-country education systems, the selection of good and necessary practices and contributing to the opportunity to adapt it to its own system".

*Dr., Müdür, Yunus Emre Enstitüsü, Priştine, Prizren ve İpek

Dr., Director, Institute Yunus Emre - Prishtina, Prizren, Peja.

ORCID 0000-0002-9072-8868

mehulker@gmail.com

Cite as/ Atıf: Ülker, M.. (2020). Türkiye ve Güney Afrika eğitim sistemlerinin: okullarda bilgi ve iletişim teknolojisi

uygulamalarına göre karşılaştırılması. Turkish Studies - Applied Sciences, 15(2), 237-252. https://dx.doi.org/10.29228/TurkishStudies.43251

Received/Geliş: 26 December/Aralık 2019

Accepted/Kabul: 24 June/Haziran 2020

Copyright (C) INTAC LTD, Turkey

Checked by plagiarism software

Published/Yayin: 26 June/Haziran 2020

CC BY-NC 4.0 
According to this, the purpose of this study is to compare the education systems of Turkey and South Africa by detecting their differences and similarities in regards to their ICT implementations. The questions sought in the study are:

1. What are the leading characteristics of the Turkish and South African education systems in the demographical and social development axis?

2. What are the prominent ICT implementations in the Turkish and South African schools? schools?

a. From past to present what are the ICT implementations made in Turkish and South African

b. What is the ICT curriculum's purpose, what are the names of the ICT courses and what is their position in the weekly course schedule in the Turkish and South African education systems?

Method: This study is a descriptive study conducted using the case study pattern of qualitative research method. The data was obtained through document analysis and was analyzed by the method of interpretation. In the data collection process, the sources of the ministries and other public institutions of Turkey and South Africa and international organizations were preferred. Among the international organizations within this scope are organizations like: World Economic Forum, World Bank, OECD and Programmed for International Student Assessment (PISA). Data has been interpreted through the stages of description, classification and association; in a subjective process, which is generated by the researcher and offers an additional perspective, which cannot be accepted by everyone and in which the meaning comes to the fore. From this process results were obtained and suggestions were made. In order to minimize errors and deficiencies, the final form of the study after the comments; was reviewed separately and finalized by the researcher and 4 people from both countries who teach in the field of ICT.

Findings: Findings were obtained from the data collected around the questions appropriate for the research purpose. In this context, the following data were included in the findings related to the first question suitable for the research purpose. The demographic data such as Turkey and South Africa's geographical position, their neighbors, population; data related to development and education system such as number of students and teacher student ratio. There is plenty of data related to the second question suitable for the research purpose. These include the purpose of using ICT-based tools in the education system, it's implementation history, and featured projects. Also, the names, durations of the courses based on ICT and their compulsory and elective status is compiled. Within this scope, the existence of the Smart School Project and Gauteng Province Paperless Classes Project was observed among the ICT based projects that stand out in South Africa. Similarly, in Turkey there are the Movement of Enhancing Opportunities and Improving Technology (FATIH) project and city and province management information system (ILSİS) called MEBBİS exist.

Results: Considering the scope and limitations of the study, the following results were obtained when the findings and the comments were taken into consideration.

1. It was found that there are significant differences between Turkey and South Africa in terms of demographic data such as geographic position, population and area.

2. When the data collected in international organizations are analyzed in the axis of development; quantitatively Turkey has better indicators than South Africa.

3. It has been observed that both countries have carried out substantially similar practices in attempts to utilize information and communication technologies in the education system. Nevertheless, it has been interpreted that compared to South Africa, Turkey is doing more pioneering and effective works.

4. In regards to the information and communication technology-based courses' compulsory or elective status and their weekly course hours in the curriculum, it is seen that Turkey is quite ahead of South Africa.

5. While in Turkey changes in the name, the load in the curriculum, status of being compulsory or elective of the Information and Communication Technology-based courses are frequently experienced, in South Africa these have remained almost constant.

Suggestions: It is considered that the demographic and development indicators of Turkey and South Africa, the obtained findings, interpretations and results related to what they did for the use of ICT in the 
teaching process provide basic data for the comparison of the education systems of these two countries. The scope and limitations of the study did not provide the opportunity to subject this data to in-depth and detailed analysis. For this reason, it is thought that it would be appropriate to carry out new and more detailed analysis studies by employing different elements of educational sciences.

Keywords: Information and Communication Technology Course, Education System, South Africa, Comparative Education, Turkey.

Öz: Bu çalışmanın amacı, Türkiye ve Güney Afrika eğitim sisteminde bilgi ve iletişim teknolojisine dayalı uygulamalarının benzerlik ve farklılıklarını karşılaştırmaktır. Bu çalışma, nitel araştırma yöntemine göre yapılmıştır. Betimsel temelli bir çalışmadır ve çalışmada nitel araştırma yönteminin, durum çalışması deseni kullanılmıştır. Veriler doküman incelemesi yoluyla toplanmış ve yorumlama yöntemiyle çözümlenmiştir. Çalışmanın bulguları iki temel başlıkta toplanmıştır. Bunlardan ilki Türkiye ve Güney Afrika'nın demografik ve kalkınmışlık göstergeleri etrafındaki bulgulardır. İkincisi ise bu iki ülkenin eğitimle ilişkili sayısal ve örgütsel yapısına ve bilgi ve iletişim teknolojileri öğretim programlarına yöneliktir. Bu kapsamda bilgi ve iletişim teknolojileri öğretim programlarının felsefi arka planı, amacı, dersin zorunlu ve seçmeli olma durumu ve haftalık ders saati sürelerine yönelik bulgular da vardır. Çalışmada elde edilen sonuçlara göre Türkiye nicelik olarak, Güney Afrika'ya göre daha iyi göstergelere sahiptir. Eğitim sisteminde bilgi ve iletişim teknolojilerinde faydalanma konusunda Türkiye, Güney Afrika'ya göre daha öncü ve etkin çalışmaların içinde olduğu yorumlanmıştır. Bunun yanı sıra her iki ülkenin önemli oranda benzer uygulamalara yer verdiği de yorumlanmıştır. Bilgi ve iletişim teknolojisine dayalı derslerin seçmeli ve ya zorunlu ders saati süresi toplamı ile öğretim kademelerine yayınlığı bakımından Türkiye'nin Güney Afrika'ya göre oldukça önde olduğu görülmüş̧ür. Bunun yanında bilgi ve iletişim teknolojisi temelli derslerin adı, seçmeli ve ya zorunlu olma durumu Güney Afrika'da nerdeyse sabit iken Türkiye'de sürekli bir değişim yaşamıştır. Elde edilen bulgu ve sonuçlara dayalı yeni ve derinlemesine araştırmaların yapılması ve bilgi ve iletişim teknolojisine dayalı uygulamaların dördüncü evresi olarak kabul edilen dijital-zeki öğrenme sistemlerini konu eden, öncü akademik çalışmaların başlatılması önerilmiştir.

Anahtar Kelimeler: Öğretim Teknolojisi, Bilgi ve İletişim Teknolojisi Dersi, Eğitim Sistemi, Güney Afrika, Karşılaştırılmalı Eğitim, Türkiye.

\section{Giriş}

Karş1laştırmalı eğitim, eğitim sistemine yönelik iyi örnekleri alma, kötü örneklerin farkına varmaya dayanan bir ödünç alma işidir. Karşılaştırmalı eğitim Bray ve Thomas (1995)'a göre "iki ya da daha fazla eğitim çalışmasındaki benzeyen ve ya farklı olanları ortaya koyma işidir". Karşılaştırmalı eğitim ile yapılan iş King (2012)'de olay ya da kararlar için ilgili bilgi ve muhtemel nedenleri sunma ve bazı sorunları açıklığa kavuşturma, gelecek araştırmacılar için hipotezler önerme, yerel özellik ve uluslararası eğilimler hakkında genel bir resim çizme şeklinde açıklanır. Şekerci vd. (2019) ise kendi eğitim sisteminizde kaliteyi artırmak için diğer ülkelerdeki iyi örnek ve uygulamaları ödünç alma girişimi olarak görür.

Özüyle karşılaştırmalı eğitim, eğitim sisteminin ana ve alt unsurları arasında benzerlik ve farklılıklar üzerine kurulu ödünç alma işidir. Karşılaştırmalı eğitim işini yapmak için bir kısım yaklaşımlara başvurulur. Bunlar arasında öne çıkanlardan biri Balcı (2009)'nın çalışmasında açıklanır. Burada karşılaştırma yapmak için iki ayrı yolun izlendiği ele alınır. Bunlardan ilki önce amaç ve politikaların ve daha sonra yönetsel yapılanma ve eğitim-süreç ölçütlerinin ortaya konulmasıyla yapılan karşılaştırmadır. İkincisi ise önce karşılaştırılacak eğitim sistemlerinin ayrı ayrı betimlenmesi daha sonra ölçüt ve betimlemelerin, bütüncül yaklaşımla ele alınmasıyla yapılan karşılaştırmadır. Karşılaştırma, Yıldırım ve Türkoğlu (2018)'na göre yatay yaklaşım, dikey yaklaşım, örnek olay incelemesi ve problem çözme başlıkları etrafında açıklanır. Bray ve Thomas (1995: 475 akt. Smit, 2011: 21)'ın çalışmasında karşılaştırma üç ana ve yirmi alt başlık etrafinda yapılır. Bu ana başlıklardan ilki coğrafi bölgelerdir. Burada; bölge ve ya ülke, ülke, eyalet ve ya 
şehir, yerleşim yeri, okul, sınıf ve bireyler alt başlıkları vardır. Bir diğer ana başlık ise coğrafi olmayan demografik özelliklerdir ve bunun alt başlıkları ise; etnik, yaş, din, cinsiyet ve diğer gruplar ile tüm nüfustur. Eğitim ve sosyal görünüm üçüncü ana başlıktır ve bunun alt başl1kları ise öğretim programı, öğretim metodu, eğitimin finansmanı, yönetim yapısı, politik değişiklikler, iş piyasası ve diğerleridir.

Karşılaştırmalı eğitim çalışmalarının gerekliliği ve eğitim sistemine katkıları oldukça fazla bilimsel çalışmada benzer ifadelerle açıklanır. Türkiye'nin ekonomik, siyasal ve toplumsal duyarlılığı, başka ülkelerle öğrenci değişimi, yürüttüğü uluslararası projeler ve Avrupa Birliği üyelik girişimi gibi nedenlere cevap olarak Erdoğan (2003)'a göre "belirli bir birikime ulaşmış ve etkin bakış açısı sunacak keşiflere ihtiyaç vardır. $\mathrm{Bu}$ ise en etkin, karşılaştırmalı eğitim çalışmalarıyla başka ve ya karşı ülke eğitim sistemlerinin keşfi, iyi ve gerekli uygulamaların seçimi ve onu kendi sistemine uyarlanma firsatı yakalamaya da katkı vermesi açılarından önemli” görülmektedir. Bu yolla eğitim sistemleri arasında varsa benzerlik ve farklıkların keşfedilebilmesine, gelişmeye açık alanlarının tespit edilmesine de firsatlar sunulur. Ayrıca karar vericilerin kararlarına ve araştırmacıların çalışmalarına katkısı da olur. Bu yönleriyle sınırlılıklarda dikkate alınarak Türkiye ve Güney Afrika eğitim sistemlerindeki bilgi ve iletişim teknolojisi (BİT) unsurlarını konu eden bir karşılaştırma çalışması, sağlaması muhtemel katkılar nedeniyle gerekli ve yerinde görülmektedir.

\section{Amacı}

Bu araştırmanın amacı, Türkiye ve Güney Afrika eğitim sistemindeki, BİT uygulamaları ile bunlara arasındaki farklılık ve benzerlikleri keşfederek iki ülke eğitim sistemini karşılaştırmaktır. $\mathrm{Bu}$ amaçla çalışmada şu sorulara cevap aranmıştır:

1. Demografik gösterge ve kalkınmışlık eksenlerinde Türkiye ve Güney Afrika ilee eğitim sistemlerinin öne çıkan özellikleri nelerdir?

2. Türkiye ve Güney Afrika'daki okullarda öne çıkan BİT uygulamaları nelerdir?

a. $\quad$ Türkiye ve Güney Afrika eğitim sisteminde, geçmişten günümüze yapılan BİT uygulamaları nelerdir?

b. Türkiye ve Güney Afrika eğitim sisteminde BİT öğretim programının; amac1, derslerinin adı, zorunlu ve seçmeli olma durumu ve ders saatleri nedir?

\section{Yöntem}

$\mathrm{Bu}$ çalışma, nitel araştırma yönteminin durum çalışması deseni kullanılarak yapılmış betimsel temelli bir çalışmadır. Veriler doküman incelemesi yoluyla toplanmış ve yorumlama yöntemiyle çözümlenmiştir.

Nitel araştırma "algıların ve olayların doğal ortamda gerçekçi ve bütüncül biçimde ortaya konması" (Yıldırım \& Şimşek, 2018: 41; 189) işidir. Durum çalışması deseni ise "bir varlığın mekâna ve zamana bağlı tanımlandığı ve özelleştirildiği” (Büyüköztürk vd., 2012: 249) çalışmadır. İşbu çalışmanın durum çalışması desenine; Türkiye ve Güney Afrika eğitim sistemlerindeki bilgi ve iletişim teknolojileri tercihleri konu olmuştur. Bu tercihlerdeki benzerlik ve farklılıklar, bu çalışmayı yapan araştırmacının yorumları etrafında karşılaş̧ırılmıştır.

\section{Veri Toplama Aracı}

$\mathrm{Bu}$ çalışmada veriler, doküman incelemesi yöntemiyle toplanmıştır. Doküman incelemesi Yıldırım ve Şimşek (2018: 41; 189)'e göre “araştırması hedeflenen olgu ve ya olgular hakkında bilgi içeren yazılı materyallerin analizi" olarak tanımlanır ve dört aşamalı bir süreci olduğu ele alınır. Bunlar özetle; kaynakların tespiti, özgünlüğü, içeriğin anlaşılmaya çalışılması, analizi ve şüphe durumunun ortadan kaldırılmasıdır. Bu bağlamda bu çalışmanın verileri de bu dört aşamalı süreçle toplanmıştır. Bunlardan ilki veri kaynaklarının tespit edilmesidir. Bu çalışmanın veri toplama 
kaynağı basılı ve ya dijital kaynaklardan oluşmuştur. Bu kaynaklar arasında kurumsal belge ve rapor, bilimsel dergi ve tez ile kitaplar yer almıştır. Bu verilerin güvenilirliği ve özgünlüğü için kurumların belge ve raporları tercih edilmiştir. Çalışmanın kapsamı da dikkate alınarak bu kurumlar Türkiye ve Güney Afrika eğitim bakanlıkları ile diğer kamu kurum kuruluş ve uluslararası organizasyonlardan oluşmuştur. Bahse konu uluslararası organizasyonlar; Dünya Ekonomik Formu, Dünya Bankası ve OECD ile OECD'nin Uluslararası Öğrenci Değerlendirme Programı (PISA)'dır. Bilimsel dergi ve tezlere ise üniversitelerin tez merkezlerinde ve bilimsel çalışmaların yayınlandığı akademik dergilerde ulaşılmıştır. Kitaplara ise daha çok basılı ve kısmen internette yayınlanan dijital kitaplardan oluşmuştur.

Veri toplamak için başvurulan ikinci süreç ise tespit edilen kaynakların incelenmesi sürecidir. Bu süreçte veri toplamak için seçilen kaynakların içerikleri, kavramsal çerçeve ve çalışma amacına uygun sorulara cevap bulacak şekilde anlaşılmaya çalışılmış ve amaca dönük veriler kayıt edilmiştir. İnceleme süreci derinleştirildikçe açıklanmakta zayıf kalan ve ya ortaya çıkan yeni durumlara göre yeni veri kaynaklarında da benzer şekilde veriler de anlaşılıp, kayıt edilmiştir. Kayıt edilen veriler bir bütünlük oluşturacak şekilde kendi içinde analiz edilerek üçüncü aşama tamamlanmıştır. Dördüncü aşama ise derlenen verilerin kullanımı konusundaki izin, alıntı ve atıf biçimlerini konu etmiştir. Bu süreçte özgün kaynaklardan; demografik ve kalkınmışlık göstergeleri ile eğitim sistemi ve BİT öğretim programı hakkındaki veriler derlenmiştir.

Türkiye ve Güney Afrika'nın demografik verileri konusunda bu çalışmada toplanan veriler, çalışmanın kapsam ve sınırlılıkları da göz önüne alınarak Öztopal ve Tomal (2019: 2585)'de açıklanan "nüfus ve yerleşme" verilerinden oluşmuştur. Türkiye ve Güney Afrika'nın kalkınmışlık göstergelerine yönelik toplanan veriler ise uluslararası kalkınma kuruluşlarının yayınlarında yer alan bir kısım karşılaştırma unsurları etrafında toplanmıştır. Eğitimle ilişkili sayısal ve örgütsel yapıya yönelik veriler ise öğrenci, öğretmen ve öğrenci başına öğretmen gibi sayısal veriler, eğitim kademleri ve öğretim programları genelinde ve BIT öğretim programı özelini konu eden çalışmalardaki verilerden oluşmuştur. Bu bağlamda Öğretim programı "öğrenme amaçlarının sıralandığı ve konu ile ilgili çıktılarının yazılı olduğu bir dokümandır” (Mylona, 1995). Öğretim programının hazırlanmasında "hedef, içerik, öğrenme-öğretme süreci ve değerlendirme ögeleri arasındaki ilişkiler bütününe bakılır" (Demirel, 2009: 5). Eğitim programlarının hedefleri, eğitim durumları (öğrenme-öğretme süreçleri) yoluyla gerçekleşir. Eğitim durumları, hedefleri gerçekleştirmek için öğrenme-öğretme durumunu etkileyen dış koşullardır (Şahin, 2014). Bu çalışmada, iki ülkenin BİT öğretim programlarındaki hedef ve öğrenme-öğretme süreci etrafinda şekillenen veriler ve kapsamla sınırlandırılmış betimleme yapılmıştır. Bu süreçte kapsam; iki ülke eğitim sisteminde BİT kullanımına yönelik yapılanlar, BİT temelli öğretim programının felsefi arka planı, amacı, dersin zorunlu ve seçmeli olma durumu ve haftalık ders saati sürelerine yönelik verilerden oluşmuştur.

\section{Verilerin analizi}

Verilerin analizinde yorumlama yöntemine başvurulmuştur. Yorumlama yöntemi Yıldırım ve Şimşek (2018: 238)'de özetle; elde edilen bulguların kendi ortamı içinde araştırmacı tarafından ortaya çıkarılan ve ek bakış açısı sunan, herkes tarafindan aynen kabul edilemeyecek ve anlamın ön plana çıktığı öznel bir süreç olarak ele alınır. Bu sürecin Dey, (1993, akt., Yıldırım \& Şimşek, 2018: 239)'e göre betimleme, sınıflandırma ve ilişkilendirme aşamaları vardır. Bu aşamalar ile veriler çözümlenmiş, bunun sonucunda; kavramsal çerçevede ve araştırma amacına uygun sorular etrafinda bulgu, yorum ve sonuçlar elde edilmiş ve bunlar ortaya konmuştur. Çalışmanın yorumlardan sonraki son şekli, hata ve eksiklikleri en aza indirmek amacıyla; araştırmacı ve her iki ülkede BİT alanında ögrretmenlik yapan dört kişiyle ayrı ayrı yeniden gözden geçirilerek son şekli verilmiştir.

\section{Bulgular}

Araştırma amacında yer alan sorulara cevap olacak veriler toplanmış ve aşağıda verilmiştir. 


\section{Demografik gösterge ve kalkınmışlık eksenlerinde Türkiye ve Güney Afrika ile eğitim sistemlerinin öne çıkan özellikleri}

Güney Afrika, coğrafi konum olarak adında yer bulduğu gibi Afrika kıtasında ve kıtanın en güneyindedir. Ülkenin kara sınırı dışında kalan bölümü bir taraftan Atlas okyanusu ve diğer taraftan da Hint Okyanusunun uzun kıyıları ile çevrilidir. Güney Afrika; Namibya, Bostwana, Mozambik, Swaziland ve tamamı Güney Afrika'nın içinde kalan Lesotho ile komşudur. Güney Afrika, South Africa at a Glance (2019) verilerine göre 1 milyon 220 bin $813 \mathrm{~km}^{2}$ fiziksel büyüklüktedir. \% 49'u erkek ve \%51'i kadından oluşan ülkenin, toplam nüfusu 57,73 milyondur. Siyasal sistem açısından ulusal, eyalet ve yerel düzeyde üç katmanlı anayasal demokrasi sistemle yönetilir. Ulusal düzeyde üç ayrı şehirde, üç ayrı başkenti vardır. Pretorya yürütmenin, Cape Town yasamanın ve Bloemfontein'de yargının başkentidir. Anayasa Mahkemesi Johannesburg şehrindedir. Yedi eyaleti olan ülkede bu eyaletlerin de başkentleri ayrı ayrıdır. Yerel düzeyde ise üç katmanda -büyükşehir, bölge ve yerel- 278 belediye ile yönetilir ve on bir resmi dili vardır.

Coğrafi olarak Asya ile Avrupa kıtasının birleşme noktasında yer alan Türkiye ise bir kısmı Avrupa'da ve büyük bir kısmı da Asya kıtasındadır. Bulgaristan, Yunanistan, Gürcistan, Ermenistan, Nahcivan, İran, Irak, Suriye ile komşudur. Kuzeyde Karadeniz, batıda Marmara denizi ve Ege Denizi ile güneyinde Akdeniz olmak üzere üç tarafında deniz vardır. Fiziksel büyüklüğü $814.578 \mathrm{~km}^{2}$ 'dir. Türkiye İstatistik Kurumu (2019) verilerine göre nüfusunun erkek ve kadın oranı \%50 ve toplam nüfusu ise 82 milyondur. Anayasal demokrasi sistemi ile yönetilir, başkenti Ankara, resmi dili Türkçe ve il sayısı seksen birdir.

Eğitim, "ekonomik büyümeyi sağlayan bir araçtır" (Özdemir vd., 2010:180) ve "beşeri sermayeyi geliştirme unsuru" (Uçkaç, 2009: 45) olarak da görülür. "Uluslararası kalite ve ya başarı göstergeleri” (Karip, 2007: 244) eğitim sisteminin değerlendirilmesinde kullanılabilir. Bu amaçla uluslararası kuruluşların kaynaklarında yine kapsam ve sınırlılıklara uygun şekilde veri derlenmiştir. Buna göre ülkelerin rekabetçilik sıralaması ve bunlara kaynaklık eden unsur ile alt unsurları da veren Dünya Ekonomik Formu, The Global Competitiveness Report başlıklı kaynaklarından bir kısım veriler derlenmiş ve grafik-1'de verilmiştir. Kapsama uygun şekilde veri derlemek için 2004'de başlayıp, 2019 yılında son bulan raporlardan faydalanılmıştır. Bu raporlardaki ülke sayısı, yıllara göre değişmektedir. Buna göre bu raporlarda en az ülke sayısı 2005 yılındaki 117 ülkedir. En çok ülke sayısı ise 114 ülke ile 2013 yılındadır.

Türkiye ve Güney Afrika'nın ülke rekabetçilik sıralamasındaki değişiklik grafik-1'de görülmektedir. 2005 yılından Türkiye 71. ve Güney Afrika 40. sıradadır. Türkiye'nin başarı sıras1 2011 yılına gelindiğinde 43. sıraya kadar yükselmiştir. Bundan sonra 2005 yılına göre daha başarılı bir sıralamada yer almış olsa da 2019 yılında 60. sırada kalmıştır. Güney Afrika ise neredeyse sürekli bir düşüş yaşamış ve 2019 yılında 61. sıraya kadar gerilemiştir.

The Global Competitiveness Report'un alt başlıklarında, eğitim sistemlerini kıyaslamada kullanılabilecek, bir kısım detaylı verilerde yer almaktadır. Buna göre kişi başı gayri safi milli hâsıla (GSMH) Türkiye için 2005 yılında 7950 \$ iken, 2018 yılında 9346 \$'a çıkmıştır. Bu dönemde Güney Afrika ise önemli dalgalanmalar yaşamış 2005 yılında 12160 \$ olan GSMH 2018 yılında 6377 \$'a gerilemiştir. Türkiye'nin 2005 y1lında 73,2 milyon olan nüfusu, 2018 yılında 82 milyon olmuştur. Güney Afrika ise 47,2 milyondan, 2018 yılında 57,7 milyona çıkmıştır. 


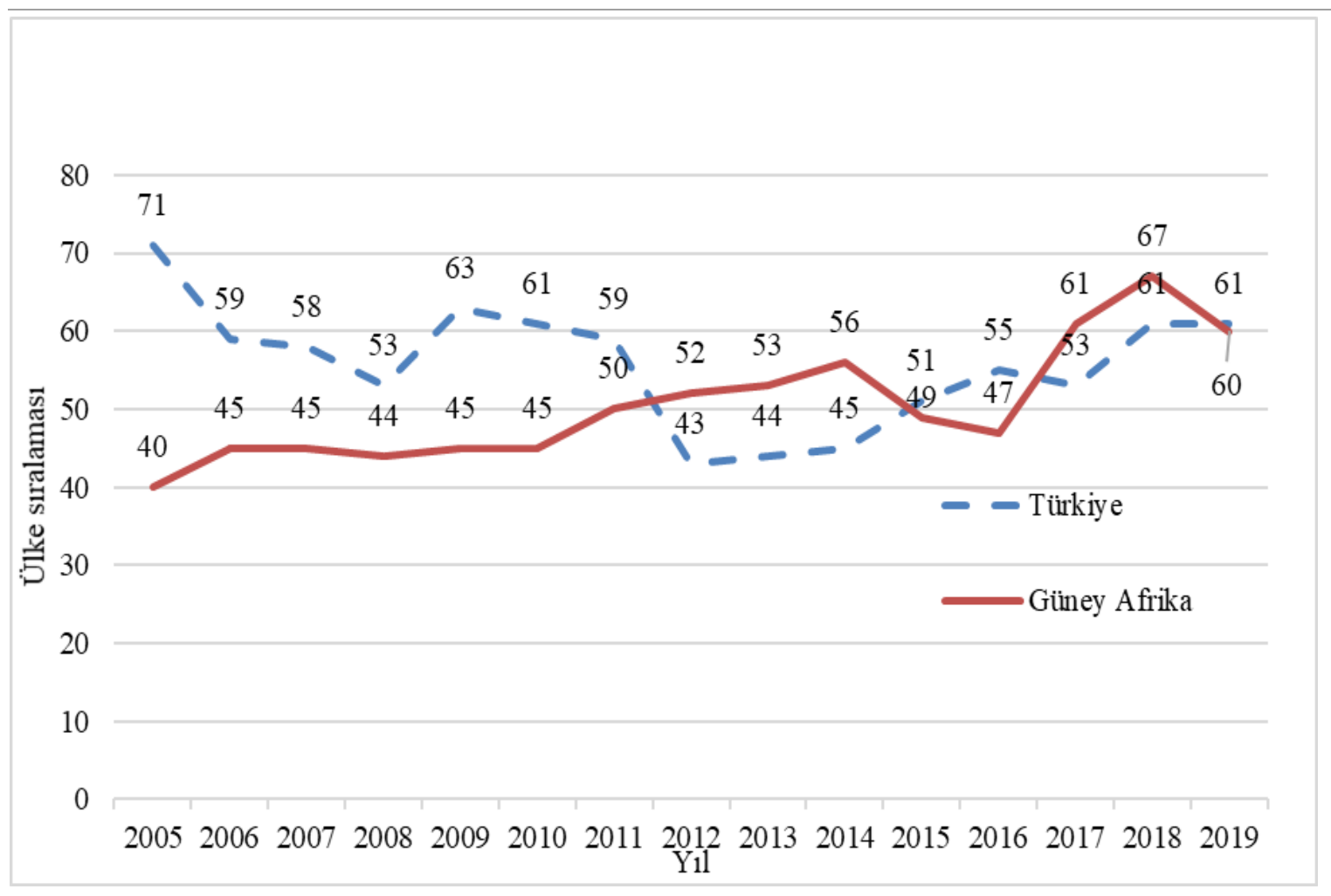

Grafik-1: Türkiye ve Güney Afrika’nın, yıllara göre dünyanın rekabetçi ülke sıralamaları grafiği.

Uluslararası organizasyonlardan biri olan Dünya Bankası (DB) yayınlarından derlenen veriler tablo-1'de verilmiştir (The World Bank, 2019). Bu kaynakta Türkiye ve Güney Afrika arasında değişik eğitim kademesinde öğrenci sayısı ve öğrenci başına öğretmen sayısını gösteren kıyaslamaya esas en güncel veriler 2015 ve 2017 yıllarında yayınlanmıştır.

Tablo-1: Türkiye ve Güney Afrika'da öğrenci başına öğretmen ve öğrenci sayıları

\begin{tabular}{cccc}
\hline Ülke & $\begin{array}{c}\text { Öğrenci başına öğretmen sayısı }(2015 \text { yıl1) } \\
\text { İlkokul ve Ortaokul }\end{array}$ & Lise & Lise Öğrenci sayısı (2017 y1li) \\
Türkiye & 21,34 & 17,57 & 11 milyon 400 bin \\
Güney Afrika & 30,32 & 27,57 & 5 milyon 052 bin 180 \\
Dünya & 23,11 & 17,34 & \\
\hline
\end{tabular}

Tablo-1'de görüldüğ̈̈ gibi 2015 yılında Türkiye'de öğrenci başına öğretmen sayısı ilk ve ortaokullar ayrı olması da dikkate alınarak ilkokullar için 18,41 ortaokullar için 27,27 ve araştırmacı tarafından hesaplanan bunların ortalaması ise 21,34 kişi iken lisede 17,57 kişidir. Bu sayı Güney Afrika'da ise ilkokulda 30,32 ve liselerde 27,57 kişidir. Öğrenci sayıları bakımından 2017 yılı verileri ise Türkiye'de lisede 11 milyondan fazla öğrenci varken Güney Afrika'da beş milyon civarında öğrenci vardır.

\section{uygulamaları}

Türkiye ve Güney Afrika'daki okullarda öne çıan bilgi ve iletişim teknolojisi

Araştırma amacında yer alan ikinci başlıktaki iki alt soruya cevap bulmak için derlenen veriler ile elde edilen bulgu ve yorumlara aşağıda yer almıştır. 


\section{Türkiye ve Güney Afrika eğitim sisteminde geçmişten günümüze bilgi ve iletişim teknolojisi uygulamaları.}

BİT araçları Güney Afrika okullarında 1980’lerde özel okullar ile iyi düzeyde mali kaynağ1 olan oldukça sınırlı sayıdaki ilkokullarda başlamıştır (Howie, vd., 2005 akt., Mdlongwa, 2012: 2). BİT'ler, bu dönem de öğrenci bilgi ve notları, okul raporu ve zaman çizelgesi gibi işlerde kullanılmıştır (Department of Education, 2015). Daha sonra BİT kullanan okul sayısı ve türü hem çeşitlenmiş ve hem de artmıştır. 1999'a gelindiğinde okulların 6,5\%'sında, 2002'de ise 12,3\%'ünde BİT araçları yer almıştır. 2003 yılında BIT kullanan okul sayısı ülkedeki 9 eyaletin hepsinde aynı seviyede gelişmese de bir kısmında önemli oranlara ulaşmıştır. Bu "Gauteng eyaletinde \%88;3 Western Cape eyaletinde 82,4\% ve Northern Cape eyaletinde \%6,3\% olmuş" (Department of Education, 2003a: 12-13) eyaletlerde ilk sıralarda yer almıştır. 2013 yılına gelindiğinde büyük bir proje ile yeni bir dönem başlamıştır. "Bu proje ile yaklaşık 28000 okulun $10 \%$ 'una bir ve ya daha çok sayıda bilgisayar dağıtılmıştır" (Mdlongwa, 2012). Daha sonraları yeni ve başka projelerde başlatılmıştır. Isaacs (2015: 61-63)'e göre bu projeler ulusal ve ya bölgesel eğitim bakanlıkları ve bağımsız taraflarca yürütülmüştür. Ulusal eğitim bakanlığınca yürütülen projeler arasında şunlar yer almıştır: Operation Phakisa ICT in Education Lab Projesi, ICT Resources for Teacher Centres, SA Connect: Broadband Access to Schools ile Virtual School projesi, DBE Television Channel ve South African National Research and Education Network (SANREN). Bölgesel eğitim bakanlığı tarafından yürütülen projeler ise şöyledir: The Internet Broadcast Project (IBP) in The Free State, Gauteng Paperless Classrooms Projesi, Western Cape Education Department's Smart Classrooms Projesi ile e-Learning Project'dir. Bağımsız taraflarca yürütülmüş projeler ise; OER Africa Project, OER@UNISA ve University of Cape Town (UCT) projeleridir.

2010'lara kadar Güney Afrika okullarındaki BİT araçları daha çok "tablet dağıtımı, akıllı tahta ve sunucu sistemi kurma ve internet bağlantıları sağlama gibi donanım temelli çalışmalardan oluşmuştur" Isaacs'ın (2015: 23). Bunun yanında Mdlongwa (2012'ya göre bu donanımların yanında “insan kaynağını geliştirme de önemsenmiştir”. 2010-2020'nin ortalarında ise öğretimi önceliğe alan çalışmaların yavaş yavaş başlatıldığı görülür. Bu amaçla yapılmış ve öne çıkmış projeler arasında Smart School Project ile Gauteng eyaleti kâğıtsız sınıflar projesi yer alır. Kâğıtsız okullar projesi Mashaba (2016)'da özetle şöyle açıklanmıştır: Ülkedeki dokuz eyaletten biri olan Gauteng Eğitim Bakanlığınca, 2015 yılında duyurulmuştur. Sınıflarda kullanılan kâğıt türü eğitim-öğretim araçları yerine geniş kapsamlı dijital teknolojilerden faydalanılması amaçlanmıştır. Bu proje uluslararası düzeyde eğitim-öğretim olanağına kavuşma fırsatı da verecektir. Projenin tahmini giderinin 1.7 milyar\$ olacağ 1 beklenmiştir. Eğitim-öğretim içerikleri 4G teknolojisi destekli ağ bağlantıları kullanılarak; tablet bilgisayar, sunucu gibi teknolojik araçlarla yapılacaktır. Yedi pilot okul ile başlayacak ve 2017-2018 yılında da eyaletteki tüm okullara yaygınlaştırılacaktır.

Türkiye'deki okullarda BİT’nin ilk uygulamaları da 1980'lerde başlamıştır. 1985 yılında “67 ilden seçilen 100 pilot ortaöğretim okuluna 550 bilgisayar dağıtılmıştır” (Keser, 1988: 167-168). 1985-1987 döneminde ortaöğretim ve mesleki ortaöğretim okullarına 2.400 bilgisayar kazandırılmıştır. 1998 yılına gelindiğinde 7.188 BİT sınıfı kurulmaya başlanmış 45.000'den fazla BİT materyali temin edilmiştir. Bunların yanında 1997 'de MEB il ve ilçe yönetim bilgi sistemi (ILLSİS) adında eğitim sistemi yönetimi ve öğretimini konu eden çalışmalar başlatılmıştır. İLSİS, günümüzde kısaca MEBBİS adıyla anılmaktadır. MEBSİS'te kapalı devre ağ yönetimi ve eğitim paçası yer alır. MEBSİS'te eğitim sistemiyle ilişkili “yatırım, kitap seçimi, burs, ilköğretim standarttı izlenmekte, RAM, yönetici, faaliyet, evrak, sosyal tesis, döner sermaye gibi 30'a yakın parça kullanılmaktadır" (Milli Eğitim Bakanlığı, 2018a). Eğitim sisteminin yönetimi ve öğretim sistemiyle uyumlu oldukça önemli bir başka gelişme 2011-2012 eğitim-öğretim yılında Eğitimde Firsatları Artırma ve Teknolojiyi İyileştirme Hareketi (FATİH) projesiyle başlatılmıştır. Bu projede 1-12'nci sınıf kademesinin tamamını kapsaması öngörülmüş̧ür. Projenin beş temel ekseni vardır. Bunlar Milli Eğitim Bakanlığı, (2010; 2018c)'de özetle; donanım ve yazılım altyapısı kurulması, ağ altyapısının 
kurulması e-içeriğin sağlanması ve yönetilmesi, öğretim programlarında etkin şekilde BİT kullanılması, bilinçli, güvenli, yönetilebilir ve ölçülebilir BİT ve internet kullanımı ile derslerde BİT kullanımı için öğretmenlere hizmetiçi eğitim başlıklıdır. Bu proje ile birçok okula LCD panelli etkileşimli tahta, internet ağ altyapısı ve çok fonksiyonlu yazıcı temin edilmiştir. Öğretmen ve öğrencilere de tablet bilgisayar dağıtılmış, tahta ve tabletlerde işlenecek ders materyali için Eğitim Bilişim Ağ̀ (EBA) kurulmuştur. Projenin birinci ve ikinci fazı tamamlanmış, üçüncü fazına geçme çalışmaları devam etmektedir. Projenin başlatıldığı dönemde kapsam ve büyüklüğü ile dünyada en önde gelen projelerden biri olduğu yorumunu yapmak mümkündür.

Türkiye'de BİT'nin eğitim sistemi içinde yer almasında, uluslararası kalkınma banka ve kurumları öncü olmuş ve önemli katkılar sağlamıştır. 1990'ların hemen öncesi ile 2010'lara kadar, mali büyüklüğü bir milyar dolar civarına ulaşan birçok projeye uygulanmıştır. Bunlar arasında Dünya Bankası kaynakl1; Milli Eğitimi Geliştirme Projesi, Temel Eğitim Projesi I. Fazı ve II. Fazı gibi projeler vardır. 2003 yılı ve sonrasında ise yine Dünya Bankası kaynaklı Orta Öğretim Projesi, Avrupa Yatırım ve Kalkınma Bankası kaynaklı Eğitim Çerçeve Projesi ve Avrupa Birliği kaynaklı Temel Eğitimi Destekleme Projesi de hayat bulmuştur. Temel Eğitim Projesi I. Fazı ile 2.802 okula 3.188 BİT sınıfı kurulmuştur. Bundan önce başlatılan Milli Eğitimi Geliştirme Projesinin, bilgisayar deneme okulları bileşeninde; 53 okula 20 bilgisayarlı laboratuvarlar kurulmuştur. 2010 yılına kadar Ortaöğretim Projesiyle, "1.629 ortaöğretim kurumuna 5.636 bilgisayar ve 5.636 yansitıcı ve 1.319 çok fonksiyonlu fotokopi makinesi satın alımı planlanmıştır" (Milli Eğitim Bakanlığı, 2018b). 2005 yılında öğretmenlere dizüstü bilgisayar kazandırma kampanyası başlatmıştır. Bu kampanyada "83.969 öğretmen dizüstü bilgisayar sahibi olmuştur" (Yıldırım ve Karaman, 2009). Uluslararas1 kurum ve kuruluşlar dışında okulların kendi imkânları ve onların dışında Milli Eğitim Bakanlığı ve başka kurum ile kuruluşlarda eğitimde bilişim teknolojisinin yer almasına yönelik çalışmaların içinde bulunmuş ve bu sisteme katkı vermiştir. Türk Telekom A.Ş., internete erişim projesi ve Ulaştırma Bakanlığı bunlarda arasında en öne çıkanlar olmuştur. Bunların dışında TÜBİTAK ve bünyesindeki Bilişim ve Bilgi Güvenliği ileri Teknolojiler Araştırma Merkezi (BİLGEM), özel ve kamu kuruluşlar, sivil toplum örgütleri de proje ve bireysel desteklerle bu sistemin oluşmasına katk1 vermiştir.

Türkiye ve Güney Afrika eğitim sisteminde bilgi ve iletişim teknolojisi öğretim programının amacı, derslerinin adı, zorunlu ve seçmeli olma durumu ve ders saatleri

Güney Afrika okullarında BİT konulu çalışmaların temel ilkeleri, Constitution of The Republic of South Africa (Act 108 of 1996) yani 1996'da Güney Afrika'da kabul edilen 108 sayıl1 kararda ele anır. Buna göre BİT kaynaklı dersler öğretim programına bağlı olarak değişik seviyelerde seçmeli ve zorunlu ders olarak yer bulur. Bu derslerde; programlama dilleri, donanım ve yazılım ile bilgi teknolojilerinin günlük yaşam, iş dünyası ve toplumdaki uygulama biçimleri öğrenen kazanımlarına konu edilir. BİT sadece bir araç olarak görülür ve "bu araçla küresel ekonomide rekabet edebilecek ve BT becerilerine sahip işgücü geliştirilmesi önemsenir. Yazılım geliştirme ve teknik destek becerileri, öğrencilerin BİT konusunda uzmanlaşması, kariyer seçimlerine firsat verecek temel beceriler kazandırması" (Department of Education, 2020a) beklenilir. Bu durum "Donanım ve sistem yazılımı, e-iletişim, sosyal ve etik konular ile programlama ve yazılım geliştirme" (Department of Basic Education, 2012) konuları olarak da ele alınır. Bu yolla öğrenen kazanımlarının bilgi teknolojisine dayalı okuryazarlık ile son kullanıcı uygulamalarını önceliğe aldığ 1 da görülür. Bunlarla "çözüm geliştirme, internet teknolojileri, bilgi yönetimi ve sosyal sonuçlara" (Department of Education, 2020b) yönelik yeterlilikler öngörülür. Okullarda BİT kullanımı sadece BİT ile ilişkili derslerde değil "10-12 ve daha ileri sınıf seviyelerindeki diğer ders uygulamalarında BIT temelli bilgi, beceri ve değerlerin yer alması da beklenir" (Department of Education, 2020a, s.8). Güney Afrika eğitim sisteminde BİT’in yer almasına yönelik yapılan önemli çalışmalar arasında Eğitim Bakanlığınca hazırlanan iki önemli strateji dokümanı da vardır. Bunlar Department of Education South Africa, (2007); Ndlovu ve Lawrence (2012)'de yer aldığ gibi eeğitimle ilgili beyaz kitap ve BİT'te öğretmen eğitimi ile uzmanlaşma kılavuzudur. BİT'in eğitim 
sisteminde yer almasıyla ilişkili ilkeler bu dokümanlarda; eşitlik, dijital kaynaklarla öğretim kalitesinin artırılması ve bunların BITT'e uyarlanmasını konu eder. Güney Afrika okullarında BIT'in etkin kullanılmasına yönelik, 2004 - 2013 dönemine yönelik bir kısım öncelikler ortaya konulmuştur. Department of Education South Africa (2015)'de bildirildiği gibi bu öncelikler “yönetici, öğretmen ve öğrencinin küresel toplumun etkin bireyleri olması için yaşam boyu öğrenme prensibi içinde BİT’ni güvenli ve yaratıcı şekilde kullanacak yeterliliklere sahip olmasına" yöneliktir. Tüm bunların yanı sıra Ndlovu ve Lawrence (2012)'e göre 2008-2012 dönemindeki BİT uygulamalarının; ekonomik ve sosyal ayrımcılığa dayanan kötü uygulamaların ortaya çıkardığı dijital bölünmeye dayanan nedenlerle başarılı olmadığı ele alınmıştır.

Güney Afrika'da üniversite öncesi eğitim kademelerindeki dersler ile bunların haftalık ders saati sayıları, Department of Education (2015)'de derlenmiştir. Öğretim programına bağlı okullardaki dersler; zorunlu dersleri ile diğer zamanlardaki ders ve etkinlikler başlığı ile iki bölüme ayrılır. Bunlar dışında mesleki ve teknik öğretim yapan okullarda ise BIT temelli program dalları da yer almaktadır. Öğretim programında yer alan zorunlu dersler 6 disiplin alanında toplanır. Bunlar; "ana dil, birinci yabancı dil, matematik bilimleri, yaşam becerileri, doğal bilimler ve teknoloji ile sosyal bilimlerdir. Dersler, okullarda ve haftanın 5 günü ve her gün yedi ders saati olmak üzere toplamda 35 ders saati sürelidir. Haftalık ders saati süresi içinde zorunlu dersler; anasınıfi, birinci ve ikinci sınıflarda yirmi üç ders saati sürelidir. Üçüncü sınıfta yirmi beş ve dört ile lise son -on ikincisınıfa kadar ise yirmi yedi buçuk ders saati sürelidir. Bunların dışında 35 ders saatlik süre "diğer zamanlardaki ders ve etkinlikler" başlıklarındaki seçmeli ders, toplantı ve moral faaliyetlerinden oluşur. BİT dersi diğer etkinlikler başlığı altında ve seçmeli dersler arasındadır. Bu ders lise düzeyindeki 10, 11 ve 12 'nci sınıf seviyesinin herhangi bir yılında, öğrenci tercihine göre belirlenecek ders saati süresine göre seçilebilir. Lise seviyesinde bilgisayar uygulamaları teknolojisi ve bilgi teknolojileri adı ile bir ve ya birkaçı, haftada dört ders saati süre ile seçilebilir. Değerlendirmelerine başvurulan öğretmenler, daha bünyesinde bilgisayar laboratuvarı bulunan okullarda çok bilgisayar uygulamaları teknolojisi ve-ve ya bilgi teknolojileri dersinin daha çok seçildiğini bildirmiştir.

Türkiye'de ise öğretim programında yer alan BİT temelli dersler 1988-89 eğitim-öğretim yılından itibaren seçmeli ders adı ile başlamıştır. 1991-1992 ile 1995-1996 eğitim-öğretim yılından 10 ve 11. sınıf kademelerinde seçmeli bilim ve teknoloji I dersi, 2000'li yılların başında da 9. ve 10 . sınıflarda "bilgisayar I-II" dersi adıyla yer almıştır. 2005 yılından sonra ilköğretim okullarında 2 ders saati süreli seçmeli ders olmuştur. 2005 yılında öğretim programı; çağın gerisinde kalması, Avrupa Birliği normlarına uyum sağlamaması gibi nedenlerle yapılandırma yaklaşımına göre değiştirilmesi, BİT derslerine de yansımış ve 2007 öğretim yılında bu dersin öğretim programında da değişiklikler yapılmıştır. Bilgi ve iletişim teknolojisi dersi, mesleki ve teknik öğretim okullarında, 2005 yılı itibariyle zorunlu genel ortaöğretim okullarında ise seçmeli ders olmuştur. 2007-2008'de Mesleki ve Teknik Eğitimin Geliştirilmesi (MEGEP) projesi (2013) kapsamında ortaya konulan bilişim teknolojileri ile ağ işletmenliği, web programcılığı, veri tabanı programcılığı ve bilgisayar teknik servisi gibi dört dal tanımlanmıştır. İlköğretim düzeyinde ise bilgisayar dersi, bilişim teknolojileri ve yazılım dersi adını almıştır. Bu dönemde ders saati süresi; 4 ve 5. sınıflarda haftada iki saat, geri kalan sınıflarda ise birer saat ve seçmeli ders statüsünde yer bulmuştur. Bu ders 2010 yılında itibaren 1- 5. sınıf seviyelerinde "serbest etkinlik" dersi ile ilişkilendirilmiş ve 6- 8. sinıf seviyelerinde ise ders saati bir saat ve seçmeli ders olarak öğretim programında yer almıştır. BİT dersleri; dersin adı, seçmeli ve ya zorunlu olması, seviyesi ve ders saati süresi bakımından sürekli bir değişim yaşamıştır. 2013-2014 öğretim yılından itibaren 5 ve 6 . siniflarda haftalık iki saat ve zorunlu, 7 ve 8 . Sinıflarda haftalık iki saat ve seçmeli ders olarak yer almıştır. 2012 yılında bilişim teknolojileri dersi öğretim programı yeniden güncellenmiştir. 2012 y1lında güncellenen öğretim programının amac1 Milli Eğitim Bakanlığı (2018d)'de derlenmiş ve şöyle özetlenmiştir: BIT dersleri ile BIT'in temel yeterliliklerini esas alan, gelişen teknolojiler ışığında her anlamda sorumluluk sahibi dijital vatandaş 
yetiştirmek amaçlanmıştır. BIT öğretim programlarının bireylerin yaşam biçiminin teknolojik destekli olması önemsenmiştir. BECTA (2009)'da yer bulan "dijital ortamda öğrenme, arttırılmış ve zenginleştirilmiş gerçeklik, mobil öğrenme ve sosyal ă̆ temaları" BİT ğretim programında yer almıştır. Burada; bilişsel, teknik ve bireysel yeterlilikler önemsenmiştir. Bu öğretim programının ortaya çıkmasında bazı kurum ve kişilerin çalışmalarından da esinlenilmiştir. Bunlar; The International Society for Technology in Education (ISTE), Öğrenciler İçin Ulusal Eğitim Teknolojileri Standartları, İrlanda'da bulunan National Council for Curriculum and Assessment ve İngiltere'de bulunan bilgi ve iletişim çalışmaları yapan NAACE'dir. Bunların dışında standart tabanlı program anlayışı ve Tomei’nin taksonomisi de BIT öğretim programına yansıtılmıştır. Öğrenen yeterlilikleri; bilgi ve iletişim teknolojisi okur-yazarlığı, dijital teknoloji, iletişim aracı ve sosyal ağ, bilgi toplumu içinde yaşarken bilgiye erişmek, yönetmek, biçimlendirmek, değerlendirmek ve oluşturmak olarak belirlenmiştir. Bu yeterlilik düzeylerinin belirlenmesinde Fraillon ve Ainley (2011) tarafından yapılan üç düzey ve altı kategorideki sınıflandırma kullanılmıştır. Bu sınıflandırmalar ve bunlara bağlı yeterlilikler şöyledir: İlki başlangıç düzeyidir. Bu düzeyde bilişim teknolojilerini kavrama, bilgiye erişme ve değerlendirme yeterlikleri beklenir. İkincisi orta düzeydir. $\mathrm{Bu}$ düzeyde bilgiyi yönetme ve bilgiyi dönüştürme yeterlilikleri önemlidir. Üçüncü düzey ise ileri düzeydir. Bu düzeyde de bilgiyi oluşturma ve paylaşma yeterlilikleri beklenir.

Bu yeterlilikler kazandırılırken, "yalnızca ofis otomasyonu öğreten yapıdan uzaklaşmak ve bireylerin yeni teknolojileri kendi kendilerine öğrenebilme ile doğru kullanımı konusunda kültür geliştirmeleri de önemsenmektedir" (Milli Eğitim Bakanlığı, 2012: 3). 2012 yılında ortaya konulan öğretim programının dört temel kazanımı öngörülmüsstür. Bunlar sırayla; bilişim okur-yazarı; bilişim teknolojilerini kullanarak iletişim kurma, bilgi paylaşma ve kendini ifade etme; araştırma, bilgiyi yapılandırma ve işbirlikçi çalışmalar; problem çözme, programlama ve özgün ürün geliştirmedir.

BİT'in okullarda yer almasıyla ilişkili son ve en güncel değişiklik ise 2017 y1lında yapılmıştır. Buna göre ortaöğretim seviyesindeki BİT temelli dersin yeni adı bilgisayar bilimi olmuştur. Bu ders Anadolu Liseleri ve Sosyal Bilimler Lisesi hazırlık sınıfinda haftada dört saat zorunlu ve Anadolu Lisesi ile diğer öğretim kademelerinde ise bir saat yerine iki saat süreli ve seçmeli ders yapılmıştır. Bunlar dışında bilgisayar bilimi dersinin Güzel Sanatlar Lisesi 9-11-12. sınıflarında 1 ders saati yerine 2 ders saat süreli ve seçmeli ders olması da kabul edilmiştir.

\section{Tartışma ve yorum}

Türkiye ile Güney Afrika'nın 2005-2019 dönemindeki Dünya rekabetçilik sıralamasına bakıldığında Türkiye'nin, Güney Afrika'ya göre daha rekabetçi bir ülke olduğunu göstermektedir. Dünya Bankası verilerine göre Türkiye; öğrenci başına öğretmen sayısı bakımından ilkokul düzeyinde, Dünya ortalamasından daha iyi, lise düzeyinde ise neredeyse Dünya ortalaması ile eş düzeydedir. Güney Afrika ise Dünya ortalamasına göre daha kötü ve ortalamadan uzaktır.

"Toplumların gelişim ve varlıklarını sürdürmesinde önemli olanlardan biri teknolojidir". (Yıldız vd., 2010:457; Avc1 vd., 2010: 465). Ayrıca teknolojik araçların, öğretim sistemine uyarlanması "hem gereklilik hem de firsattır" (UNESCO, 2009). Bu gerekliliği Özdemir vd. (2010) bilgi toplumu kavramı etrafinda şöyle açıklar: Sadece okuma yazma ve aritmetik becerilerle değil, (mesela) temel bilgisayar becerileri ile donatılmış ve siyasal, sosyal, tarihsel sistemlerle tanışmış olmasını bir gereklilik olarak görür. Eğitimde kâğıt kalemin yer almasıyla başlayan teknolojik süreç, bilgi çağıyla daha da etkinleşmiştir. 20'nci yüzyılın üçüncü çeyreğinde başlayan bilgi çağı "insanlık tarihinin uygarlık düzeyinin son halkasıdır" (Toffler, 1981). Bilgi çağı teknolojinin gelişimi ve bilgisayarın teknolojik araçlar arasında etkin bir şekilde yer almasıyal çok daha etkin bir konuma gelmiş ve neredeyse tüm sistemleri etkilemiştir. Teknolojinin, eğitim sistemiyle ilişkisini 1950 ve sonrası dönem bağlamında baktığımızda şunları ele almak mümkündür. 1950'lerde görsel-işitsel, tv, radyo gibi teknolojik araçlar eğitim siteminde yer almaya başlamıştır. 1980'lerde ise bilgisayar ve çevre bilimlerinin eğitim sisteminde de etkinliği artmıştır. Eğitim sisteminde bilgisayarla öğretim ve 
devamında BİT ile öğretim gibi adlar kullanılır olmuştur. 1990'larda BIT’nin eğitim sistemine uyarlanmasında Keser (1988: 164)'e göre donanım, yazılım, öğretim programı ve materyal geliştirme gibi boyutlara odaklanılmış ve bu sürecin devamında bilgisayar eğitiminden-bilgisayar destekli eğitime doğru bir geçiş süreci yaşanmıştır. BİT ile "1980-90 döneminde BİT becerilerinin geliştirilmesine, 1990-2010 döneminde bilgi ve bilgi toplumu becerilerinin geliştirilmesine, 2010 ve sonrası dönemde ise bilgi toplumu becerilerin yanında çevresel, toplumsal ve etik duyarlığa sahip bireyler yetiştirilmesine yönelik çalışmalar yapılmıştır” (Bardakçı, 2013: iv). İnternet ile BIT temelli öğretim bir anlamda hızlı ve baş döndürücü bir dönüşüm yaşanmasına da vesile olmuştur. Teknolojik dönüşüm The Paisano (2008, akt., Y1lmaz, 2014: 16)'ya göre Web 1.0'dan başlayıp Web 4.0'e giden dört ayrı dönem ile açıklanır. Buna göre "Web 1.0 sadece okunabilir temellidir. Web 2.0 ile katılımc1, okunabilir ve yazılabilir teknolojiye geçiş yapmıştır. Web 3.0 teknolojisi ise kişiye uygun ortam ve içeriklerle uyarlanabilir, algılanabilir akıllı web uygulamaları ortaya çıkarmıştır. Devam eden gelişme ekseninin son halkası ise web 4.0'dür. Bu halkada yapay zekâ ve zeki öğrenme sistemlerine geçiş yer almaktadır".

1980 ve sonrası için teknolojinin eğitim sistemine uyarlanmasına yukarıdaki kapsam ve Türkiye ile Güney Afrika'daki uygulamalar ekseninde baktığımızda şu yorumları yapmak mümkündür. Türkiye ve Güney Afrika'da BİT'nin eğitim sistemine uygulanması 1980'li yıllarda başlatılmıştır. Bu dönemde iki ülkede; BİT donanımı ve yan ürünleri temin edilmesi, BİT temelli öğretim programı ve materyal geliştirme çabaları olmuştur. BİT idari işlerde kullanılmaya başlanmış ve daha çok bilgisayar okuryazarı yetiştirme öncelikli olmuştur. 1990'ların ortasına doğru Türkiye, Güney Afrika'ya göre çalışmalarını daha çok yaygınlaştırmış ve büyütmüştür. Bu bağlamda öğretim yazılımı ve ağ sistemleri de eğitim sistemine uyarlanmaya çalışılmıştır. Bilgisayar eğitimindenbilgisayar destekli eğitime doğru bir geçiş süreci yaşanmıştır. Güney Afrika'da BíT strateji dokümanları ortaya konmuştur. Buna karşın Türkiye, Güney Afrika'ya göre daha kapsamlı projeler yapmış, uluslararası kaynaklardan daha çok faydalanmış ve dahası BİT temelli okul yönetimi ile ögretim destek mekanizmasını daha etkin kılacak uygulamalara hayat vermiştir. Bu bağlamda günümüzde MEBBİS adıyla anılan İl ve ilçe yönetim bilgi sistemi (ILLSİS)'in altyapısını 1997'de kurmaya başlamıştır. 2008'de Eğitimde Fırsatları Artırma ve Teknolojiyi İyileştirme Hareketi (FATIH) projesini başlatmıştır. Güney Afrika ise teknolojik değişimin çok hızlı yaşanmasının yanında Türkiye'ye göre daha dar kapsamlı ve büyüklükteki "akıllı okullar projesi" ve "kâğıtsız sınıflar projesi” gibi projeleri 2013'lerde uygulamaya başlamıştır. Yapay zeka ve zeki öğrenme sistemlerine geçiş evresi içinde olduğumuz bugünlerin, her iki ülkede de somut örneklerine rastlanmamıştır. Bu konuda sadece Milli Eğitim Bakanı Selçuk: Yapay zekâ eğitiminde dünya lideri olacağız, (Sputniknews, 27.03.2019) başlıklı haberde Türkiye'nin yapay zekâ ve ya zeki öğrenme stratejileri konusunda hazırlık yaptığı, bu amaçla yakın dönemde kamuoyuna açıklanacak bir taslak metnin tamamlamak üzere olduğu bilgisi geçmiştir.

Türkiye'de ilköğretim ve genel ortaöğretimde; bilim ve teknoloji I, bilgisayar I-II, bilgi ve iletişim teknolojisi, bilişim teknolojileri ve yazılım dersi bilgisayar bilimi gibi ders adları; Güney Afrika'da seçmeli bilişim teknolojileri dersi adıyla kullanılmaktadır. Türkiye'de dersin seçmeli ve ya zorunlu ders olma durumu ve ders saati süresi s1k s1k değişmiştir.

Türkiye'de BIT ile temel yeterlilikleri esas alan, gelişen teknolojiler 1şı̆̆ında her anlamda sorumluluk sahibi dijital vatandaş yetiştirmek amaçlanmıştır. Dijital ortamda öğrenme, arttırılmış ve zenginleștirilmiş gerçeklik, mobil öğrenme ve sosyal ağ temaları öğretim programında yer almıştır. Burada; bilişsel, teknik ve bireysel yeterlilikler önemsenmiştir. Güney Afrika'da ise BİT, öğretim sürecinde sadece bir araç olarak kullanılması önemsenmiştir. Bu araçla küresel ekonomide rekabet edebilecek, bilgi teknolojisine dayalı okuryazarlık ile son kullanıcı uygulamaları ve daha ileri sınıf seviyelerindeki diğer derslerdeki uygulamaların yapılması planlanmıştır. 


\section{Sonuçlar}

Çalışma kapsamı ve sınırlılıkları da dikkate alınarak elde edilen bulgu ve bunlar üzerine yapılan yorumlara göre şu sonuçlar elde edilmiştir.

1. Çalışma kapsamında derlenen coğrafi konum, nüfus ve yüzölçümü gibi demografik veriler açısından Türkiye ile Güney Afrika arasında önemli farklılıkların olduğu görülmüştür.

2. Kalkınmışlık ekseninde, uluslararası organizasyonlarda derlenen veriler analiz edildiğinde; nicelik olarak Türkiye, Güney Afrika’ya göre daha iyi göstergelere sahiptir.

3. Eğitim sisteminde bilgi ve iletişim teknolojilerinde faydalanma girişimleri konusunda her iki ülkenin de önemli oranda benzer uygulamalar yaptığı görülmüştür. Buna rağmen Türkiye'nin, Güney Afrika'ya göre daha öncü ve etkin çalışmaların içinde olduğu da yorumlanmıştır.

4. Bilgi ve iletişim teknolojisine dayalı derslerin, öğretim programında seçmeli ve ya zorunlu olma durumu ile haftalık ders saati süreleri bakımından, Türkiye'nin Güney Afrika'ya göre oldukça önde olduğu görülmektedir.

5. Bilgi ve iletişim teknolojisi temelli derslerin adı, öğretim programındaki yükü, seçmeli ve ya zorunlu olma durumundaki değişiklikler ise Türkiye'de sık sık yaşanırken, Güney Afrika'da neredeyse sabit kalmıştır.

\section{Öneriler}

Türkiye ve Güney Afrika'nın demografik ve kalkınmışl1k göstergeleri, öğretim sürecinde BIT kullanımına yönelik yaptıklarına yönelik elde edilen bulgu, yorum ve sonuçların iki ülkenin eğitim sistemini karşılaştırmaya temel düzeyde veri temin ettiği değerlendirilmektedir. Çalışmanın kapsamı ve sinırlılikları bu verileri, derinlemesine ve detaylı bir analize tabi tutma firsat1 vermemiştir. Bu nedenle eğitim bilimlerinin değişik unsurlarını da işe koşarak, yeni ve daha detaylı analiz çalışmalarının yapılmasının yerinde olacağı önerilmektedir.

Ayrıca bilgi ve iletişim teknolojisine dayalı uygulamaların dördüncü evresi olarak kabul edilen dijital-zeki öğrenme sistemlerini konu eden, öncü akademik çalışmaların başlatılması önerilmiştir.

\section{Etik Kurul Onayı Beyanı}

Çalışmada araştırma ve yayın etiğine yönelik; ilke ve kurallara uyulmuştur. Bu anlamda başkalarına ait ölçek, anket ve fotoğraf kullanılmamıştır. Araştırmacının yorumuna dayalı bu çalışma da veri toplamak için görüşüne başvurulmuş başka kimse yoktur. Ayrıca bu çalışma klinik ve deneysel insan ve hayvanlar üzerine yapılmış bir çalışma da değildir. Bu nedenle etik kurul raporuna ihtiyaç duyulmamış ve bu nedenle etik kurul raporuna başvurulmamıştır.

\section{Kaynakça}

Avcı, Ü., Kurtoğlu, M. \& Seferoğlu, S.S. (2010). Türkiye'de planlı kalkınma ve teknoloji politikaları 10 - XII. Akademik Biliş̧im Konferansı Bildirileri, Muğla Üniversitesi.

Aynal, S. (2012). Karşılaş̧ırmalı eğitim yansımaları. Pegem Akademi.

Aziz, A. (2015). Sosyal bilimlerde araştırma yöntemleri ve teknikleri. Nobel yayınları.

Balc1, A. (2009). Karşılaştırmalı eğitim sistemleri. Pegem Akademi yayınları

Bardakc1, S. (2013). Bilişsim teknolojilerinin eğitime entegrasyonu: farkl amaç, politika, uygulama, etki ve eleştiriler üzerine bir inceleme. Yayınlanmamış doktora tezi, Ankara Üniversitesi, Eğitim Bilimleri Enstitüsü, Ankara. 
Bilgin, N. (2006). Sosyal bilimlerde içerik analizi teknik ve örnek çalışmalar. Siyasal Kitabevi

Çelik, A. (2019). Sosyal bilgiler öğretmen adaylarının sosyal bilgiler dersinde kullanılabilecek edebi ürün tasarlama deneyimlerinin incelenmesi, Turkish Studies Educational Sciences. 14(5): 2233-2253. http://dx.doi.org/10.29228/TurkishStudies.29342

Department of Basic Education. (2020a). Information technology, learning programme guidelines, National Curriculum Statement Grades 10-12 (General). https://gifs.africa/wpcontent/uploads/2020/05/Grade-10-12-Information-Technology-Notes.pdf

Department of Education, (2020b). Computer applications technology. Curriculum and Assessment Policy Statement Grades 10-12. https://gifs.africa/wp-content/uploads/2020/05/Grade-1012-Information-Technology-Notes.pdf

Department of Education (2015). National policy pertaining to the programme and promotion requirements of the National Curriculum Statement, Grades R - 12.

https://www.education.gov.za/Portals/0/Documents/Policies/PolicyProgPromReqNCS.pdf? ver $=2015-0$

Demirel, Ö. (2009). Kurmadan uygulamaya eğitimde program geliştirme. Pegem Akademi yayınları.

Erdoğan, İ. (2003). Karşılaştırmalı eğitim: Türk eğitim bilimleri çalışmaları içinde önemsenmesi gereken bir alan. Gazi Üniversitesi Eğitim Bilimleri Dergisi, 1(3): 265-283.

Government Gazette, (2004). White paper on transforming learning and teaching through information and communication technologies (ICTs), Notice 1869 of 2004. Republic of South Africa, Vol. 470 (26734). Formeset Printers.

Howie, S., Muller, A. \& Paterson, A. (2005). Information and communication technologies in South African secondary schools. HSRC.

Isaacs, S. (2015). A baseline study on technology-enabled learning in the african and mediterranean countries of the commonwealth report. Commonwealth of Learning.

Karip, E. (2007). İlköğretimde kalite: Avrupa Birliği kalite göstergeleri çerçevesinde kalitenin değerlendirilmesi. (Ed.: Özdemir, S., Bacanl, H. ve Sözer M.). Türkiye'de okul öncesi eğitim ve ilköğretim sistemi temel sorunlar ve çözüm önerileri (211-267). Adım Ajans.

Keser, H. (1989). Türk okul sisteminde bilgisayarların kullanılması. A.Ü. Eğitim Bilimleri Fakültesi Dergisi, 22 (1):189-224.

King, E. J. (2012). Comparative studies and educational decision. Routledge Taylor \& Francis.

Mashaba, S. (2016, January 17). Paperless classrooms expand in Gauteng. Sovetan Live, ss. A9.

Mdlongwa, T. (2012). Information and communication technology (ICT) as a means of enhancing education in schools in South africa: challenges, benefits and recommendations. Policy Brief, Africa Institute Of South Africa Briefing, No. 80. http://www.ai.org.za/wpcontent/uploads/downloads/2012/10/No.-80.-ICTas-a-means-of-enhancing-Education-inSchools-in-South-Africa.pdf

Mesleki ve Teknik Eğitimin Geliştirilmesi (MEGEP) projesi, (2013). Bilişim teknolojileri alanı web sitesi: Modüller. http://www.megepbilisim.com/moduller/

Milli Eğitim Bakanı Selçuk: Yapay zekâ eğitiminde dünya lideri olacağız, (Sputniknews, 27.03.2019). https://tr.sputniknews.com/turkiye/201903271038448956-meb-ziya-selcukyapay-zeka-egitimi-dunya-liderligi/. 
Milli Eğitim Bakanlığı, (2010). Eğitimde FATİH projesi proje uygulama planı. MEB Eğitim Teknolojileri Genel Müdürlüğü.

Milli Eğitim Bakanlığı, (2012). Ortaokul ve İmam Hatip Ortaokulu bilişim teknolojileri ve yazılım dersi (5, 6, 7 ve 8. sinıflar) ögretim programı. Talim ve Terbiye Kurulu Başkanlığı.

Milli Eğitim Bakanlığı, (2018a). Milli Eğitim Bakanlığ MEBBiS bilişim sistemleri. http://mebbis. meb.gov.tr/.

Milli Eğitim Bakanlığı, (2018b). Ortaöğretim projesi. Web:http://oop.meb.gov.tr/ index.php?option=com_content $\&$ view $=$ article $\&$ id $=91 \&$ Itemid $=200$.

Milli Eğitim Bakanlığı, (2018c). Proje hakkında. http://FATiHHprojesi.meb.gov.tr/.

Milli Eğitim Bakanlığı, (2018d). Öğretim programları. Web:http://ttkb.meb.gov.tr/.

Mylona, K. (1995). Designing the four years tourism managment curriculum. Journal of Travel Research, 34(1): 68-72.

Ndlovu, S. N. \& Lawrence, D. (2012). The quality of ICT use in South African classrooms, Conference Strategies to Overcome Poverty\&Inequality Towards Carnegie III. http://www.mandelainitiative.org.za/images/docs/2012/papers/197_Ndlovu_The quality of ICT use in South African classrooms.pdf.

OECD, (2019) PISA 2018: Highlight indicators. https://www.oecd.org/pisa/publications/pisa-2018results.htm

Özdemir, S., Yalın, H. İ. \& Sezgin, F. (2012). Türk eğitim sistemi, yasal temelleri ve sorunları. Eğitim bilimine giriş. Pagem Akademi Yayınları.

Öztopal, S. \& Tomal, N. (2019). Lise siyasi coğrafya konularında öğrenci başarılarına yönelik öğretmen görüşleri, Turkish Studies Educational Sciencesi, 14(5): 2581-2600. http://dx.doi.org/10.29228/TurkishStudies.30198

Şahin, M. (2014). Üniversite Öğretim Elemanlarının Sınıf İçi Öğretimsel Davranışlarına Yönelik Öğrenci Görüşlerinin İncelenmesi. (Çankırı Karatekin Üniversitesi Örneği). Turkish Studies - International Periodical For The Languages, Literature and History of Turkish or Turkic. 9(11), 499-515

Şekerci, R,. Gök, R \& Özçetin, S. (2019). Türk Eğitim sistemi ile diğer ülkelerin eğitim sistemlerinin karşılaştırılmasına ilişkin aday öğretmenlerin görüşleri. Journal of Global Sport and Education Research, 2(1):10-23. https://dergipark.org.tr/tr/pub/jogser/issue/46564/562655.

Smit, B. (2011). Themes in South African educaton. (Edt: Lemmer, E. ve Wyk, N.). South Africa.

South Africa Goverment-Glance, (2016). South Africa at a glance. https://www.gov.za/aboutsa/south-africa-glance

Thomas, R. M. (1990). International comparative education. Pergamon Pres

Türkiye İstatistik Kurumu, (2019). Türkiye İstatistik Kurumu. http://www.tuik.gov.tr/

Toffler, A. (1981). Üçüncü dalga, (Çev.: Ali Seden). Altın Kitap yayınevi.

Uçkaç, A. (2009). Ekonomik kalkınma ve küreselleşme sürecinde eğitim. Yayınlanmamış doktora tezi. İstanbul Üniversitesi Sosyal Bilimler Enstitüsü, İstanbul.

The World Economic Forum, 2006-2007. (2019). The Global Competitiveness Report 2006-2007 http://www3.weforum.org/docs/WEF_GlobalCompetitivenessReport_2006-07.pdf 
The World Economic Forum, 2019. (2019). The Global Competitiveness Report, 2019. http://www3.weforum.org/docs/WEF_TheGlobalCompetitivenessReport2019.pdf

The Paisano, (2008). WEB teknolojilerinin gelişim süreci. https://thepaisano.files.wordpress.com/2008/03/webtimeline.jpg.

The World Bank, (2019). Pupil -teacher ratio, lower secondary- Turkey, South Africa, World. https://data.worldbank.org/indicator/SE.SEC.ENRL.LO.TC.ZS?locations=TR-ZA-1W. Mayı,

Wolhuter, C. C. (2006), Teacher training in South Africa; past, present and future, Education Research and Perspectives, 33(2):124-139

Yıldırım, S. \& Karaman, S. (2009). Her öğretmene dizüstü bilgisayar kampanyasına katılan öğretmenlerin bilgisayarları kullanım durumları: Erzurum ili örneği. Selçuk Üniversitesi Ahmet Keleşoğlu Eğitim Fakültesi Dergisi, 27(0): 117-132

Yıldırım, C. \& Türkoğlu, A. (2018). Karşılaştırmalı eğitim yansımaları: on yıl sonra. Adnan Menderes Üniversitesi Sosyal Bilimler Enstitüsü Dergisi, 5(1): 31-45. https://doi.org/10.30803/adusobed.323374

Yıldız, B., Ilgaz, H. \& Seferoğlu, S. S. (2010). Türkiye'de bilim ve teknoloji politikaları: 1963'den 2013'e kalkınma planlarına genel bir bakış. XII. Akademik Bilişim Konferansı Bildirileri. 457-464.

Yılmaz, K. G. F. (2014). E-öğrenme ortamlarında yansıtıcı düşünme etkinliklerinin, öğrencilerin akademik başarısına, sosyal buradanlığına ve güdülenmesine etkisi, Yayınlanmamış Doktora Tezi. Ankara Üniversitesi, Eğitim Bilimleri Enstitüsü: Ankara. 